\title{
Morphology of the tubercle of Zuckerkandl and its importance in thyroid surgery
}

\author{
A Rajapaksha, R Fernando, N Ranasinghe, S Iddagoda
}

\begin{abstract}
The tubercle of Zuckerkandl (ZT) is an embryological remnant of the thyroid gland. Its close relationship to the recurrent laryngeal nerve (RLN) makes it an important surgical landmark. Presence and size of the ZT was prospectively assessed during thyroidectomies done at a single surgical unit during 2013. Eighty patients were included in the study. Closest distance and relationship of the ZT to the RLN was measured. Median age was 48 years (range $20-75$ years). The ZT was present in $72(90 \%)$ patients at least on one side and $55(69 \%)$ patients on both sides. Grade III tubercles were found in 17 (21.25\%) patients. Average distance between RLN and the ZT was $1.2 \mathrm{~mm}$ posteriorly or posteromedially. In the majority $(79 \%)$ RLN was lying at a distance of $\leq 1 \mathrm{~mm}$. Pressure symptoms were present in $19(23.75 \%)$ patients and it was not related to the presence of grade III tubercles ( $p$ $=0.207$ ).
\end{abstract}

Ceylon Medical Journal 2015; 60: 23-24

\section{Introduction}

The tubercle of Zuckerkandl (ZT), first described in 1902 by Emil Zuckerkandl is an embryological remnant of the thyroid gland. It is commonly seen as a thickening or a nodule in the posterior aspect of the gland. The ZT is macroscopically distinguishable from the rest of the gland during surgery. The surgical importance of the tubercle was not initially appreciated until its close relationship to the recurrent laryngeal nerve (RLN) was recognized. It is a useful landmark to identify the RLN. This also implies that RLN may be damaged if the tubercle is not identified and carefully dealt with. Complete excision of the tubercle is also important as unresected tubercles are a common cause for recurrence of goitre following thyroidectomy. Studies have shown an association between pressure symptoms and enlarged tubercles [1].

\section{Methods}

A descriptive study was carried out at the University Surgical Unit of North Colombo Teaching Hospital on patients who underwent total thyroidectomy from $1^{\text {st }}$ January 2013 - 31 $1^{\text {st }}$ December 2013. All surgeries were performed by a single surgeon. Hemithyroidectomies and Revision thyroidectomies were excluded from the study.

Presence and location of the ZT were noted intraoperatively. A sterile needle with calibrations in millimeters was kept on the gland and the closest distance to the RLN was approximately measured. Size of the tubercle was measured in removed specimens using a Vernier caliper and grading was done according to the grading proposed by Pelizzo et al [2]. The relationship of the ZT to the RLN was assessed in mediolateral and anteroposterior planes during the surgery. Intra-operative photographs were taken to visualize the ZT and its relationship to the RLN. All thyroid specimens were also photographed immediately after surgery. Preoperative presence or absence of pressure symptoms were documented and compared with presence or absence of a grade III tubercle.

\section{Results}

A total of 80 patients were included in the study. Median age was 48 years (range 20-75 years). Seventy seven were females and three were males. The ZT was present on the right side in $70(88 \%)$ patients and on the left side in $57(71 \%)$ patients and on both sides in 55 $(69 \%)$ patients. It was absent on both sides in $8(10 \%)$ patients. Grade III tubercles were found in $17(21 \%)$ patients (Table 1).

Table 1. Grades of Zuckerkandl tubercle in each side

\begin{tabular}{ccc}
\hline Grade & Right side & Left side \\
\hline I & 26 & 32 \\
II & 32 & 17 \\
III & 12 & 8 \\
Absent & 10 & 23 \\
Total & 80 & 80 \\
& & \\
\hline
\end{tabular}

University Surgical Unit, North Colombo Teaching Hospital, Ragama, Sri Lanka.

Correspondence: AR, e-mail: <anuradha.surgery@gmail.com>. Received 12 July and revised version accepted 29 December 2014. Competing interests: none declared. 


\section{Relationship to recurrent laryngeal nerve}

Out of the 72 patients who had ZT, the RLN lay directly on the tubercle in $49(68 \%)$ patients (Table 2). In majority of patients $63(88 \%)$ RLN was found at a distance of $1 \mathrm{~mm}$ or less. Average distance between the RLN and the ZT was $1.2 \mathrm{~mm}(1.1 \mathrm{~mm}$ in right side and $1.3 \mathrm{~mm}$ in left side). In the patients who had ZT, the RLN was situated either posterior or postero-medial to the tubercle. Pressure symptoms were present in 19 (24\%) and it was not related to the presence of a grade III tubercle $(p=0.207)$.

\section{Discussion}

These findings show a higher incidence of the ZT among this Sri Lankan cohort (90\%). Similar to other studies the incidence of ZT was higher on the right side [3]. This can be due to the embryological difference of the two sides in relation to pharyngeal arches. Various studies have been done on the incidence of ZT and its relationship to the RLN in many countries. They have showed different incidences among different populations. Incidence of ZT has been reported as $80.2 \%$ in Malaysia, $77 \%$ in Italy, $63 \%$ in Australia, $88.75 \%$ in Turkey and $45 \%$ in Rome. The incidence of ZT among Sri Lankan population had not been studied previously [1,2,4-6].

The ZT is an important anatomical feature of the thyroid gland though very little attention is given to it during dissection. New information regarding fascial planes separating ZT from RLN highlight the importance of recognizing it [7]. Pressure symptoms are associated with grade III tubercles according to previous studies, but this cohort failed to show any significant association [1].

It is recommended that the dissection of the gland should commence from right side if it is feasible, as the incidence of ZT is higher in right side. Dissection of one side will provide more space to visualize the important structures on the other side. Neurovascular arrangement

\section{Table 2. Location and the distance between Zuckerkandl Tubercle and recurrent laryngeal nerve}

\begin{tabular}{ccccc}
\hline $\begin{array}{c}\text { Distance } \\
\text { to RLN }\end{array}$ & Right & $\begin{array}{c}\text { Right } \\
\text { Location } \\
\text { (Posterior } / \\
\text { Postero-medial) }\end{array}$ & Left & $\begin{array}{c}\text { Left } \\
\text { Location } \\
\text { (Posterior / } \\
\text { Postero-medial) }\end{array}$ \\
\hline $0 \mathrm{~mm}$ & 32 & $16 / 16$ & 17 & $8 / 9$ \\
$1 \mathrm{~mm}$ & 6 & $5 / 1$ & 8 & $7 / 1$ \\
$2 \mathrm{~mm}$ & 21 & $12 / 9$ & 27 & $10 / 17$ \\
$3 \mathrm{~mm}$ & 11 & $6 / 5$ & 5 & $1 / 4$ \\
Total & 70 & $39 / 31$ & 57 & $26 / 31$ \\
Average & & & & \\
distance & $1.1 \mathrm{~mm}$ & $1.3 \mathrm{~mm}$ & & \\
\hline
\end{tabular}

around the ZT and parathyroid glands are extremely important in thyroid and parathyroid surgeries. In this cohort the RLN laid either posterior or postero-medial to the ZT. None of our patients had an anteriorly located nerve in relation to $\mathrm{ZT}$. The close relationship between ZT and the RLN, makes it a useful landmark to identify the RLN and hence prevent inadvertent damage. Though there was no significant association between pressure symptoms and grade III tubercles in this cohort it could be due to the small sample size.

\section{Limitations}

This was a study on a selected group of patients with goitres. The distance to the RLN was measured approximately and was done using a non-standard instrument. Further studies including cadaveric studies are needed for a comprehensive evaluation of the morphology and incidence of the Tubercle of Zuckerkandl and its relations to the neighboring neurovascular structures in Sri Lankans.

\section{Declaration of Interest}

There are no conflicts of interest.

\section{References}

1. Hisham AN and Aina EN. Zuckerkandl's tubercle of the thyroid gland in association with pressure symptoms: A coincidence or consequence? ANZ J Surg 2000; 70: 251-3.

2. Pelizzo MR, Toniato A and Gemo G. Zuckerkandl's tubercle: an arrow pointing to the recurrent laryngeal nerve (constant anatomical landmark). J Am Coll Surg 1998; 187: 333-6.

3. Gurleyik E and Gurleyik G. Incidence and Surgical Importance of Zuckerkandl's Tubercle of the Thyroid and Its Relations with Recurrent Laryngeal Nerve. ISRN anatomy 2012; 1: 1-5.

4. Gauger PG, Delbridge LW, Thompson NW et al. Incidence and importance of the tubercle of Zuckerkandl in thyroid surgery. Eur J Surg 2001; 167: 249-54.

5. Yalcin B, Tatar I and Ozan H. The Zuckerkandl tubercle and the recurrent laryngeal nerve. American Journal of Surgery 2008; 196: 311-2.

6. Gravante G, Delogu D, Rizello A and Filingeri V. The Zuckerkandl tubercle. Am J Surg 2007; 193: 484-5.

7. Serpell JW. New operative surgical concept of two fascial layers enveloping the recurrent laryngeal nerve. Ann Surg Oncol 2010; 17: 1628-36. 